\title{
Ensaio sobre a sublimação
}

Tania Rivera

Psicanalista e professora do Departamento de Psicologia Clínica da Universidade de Brasília (UnB) 


\section{Ensaio sobre a sublimação}

O presente ensaio discute a noção de sublimação em psicanálise, aproximando-a da noção freudiana do Estranho (Unheimliche). Ressalta-se a concepção contraditória do sublime no Romantismo para destacar no Estranho a estrutura de arranjo significante contraditório por excelência, sem síntese possível e ligado à possibilidade de se elevar "um objeto qualquer à dignidade da Coisa", segundo a célebre fórmula de Lacan. Propõe-se conceber, em tal elevação, também, um realce da vertente de in-dignidade da Coisa.

Palavras-chave: psicanálise, sublimação, Estranho (Unheimliche), Coisa (das Ding)

\section{On sublimation}

The paper discusses the psychoanalytical notion of sublimation from the perspective of Freud's the Unheimliche, which is nothing but a structure of contradictory signification without synthesis. The Unheimlich is responsible, in Lacan's phrase, for the elevation "of any given object to the dignity a thing (Ding)". But such a process could also be the occasion for the glancing at the indignity of a thing.

Key words: psychoanalysis, sublimation, das Unheimliche, das Ding
Belo é o que foi um dia sexual, segundo Freud. Na primeira incidência do termo sublimação em sua obra, ele defende que o ocultamento do corpo promovido pela civilização mantém acesa a curiosidade sexual, e que esta pode ser "desviada (sublimada) para a arte" caso o interesse se afaste dos genitais em prol da forma do corpo como um todo. "Parece-me indubitável", afirma ele em uma nota acrescentada em 1915 a esse trecho

que o conceito do 'belo' enraíza-se na excitação sexual e, em sua origem, significava aquilo que estimula sexualmente. Relaciona-se a isso o fato de jamais podermos achar realmente belos os genitais, cuja visão provoca a mais intensa excitação sexual (Freud 2, p. 148).

Quase quarenta anos antes, a Origem do mundo, de Gustave Courbet, já punha em xeque tal posição, ao fazer da crua apresentação da genitália feminina uma obra, não sem causar certo escândalo. Curiosamente, esse quadro pertencerá, várias décadas depois, a Jacques Lacan, que desenvolverá de forma marcante a questão do sublime na psicanálise a partir de Freud. Mesmo nas paredes de Lacan, contudo, a obra de Courbet permanecerá oculta sob uma pintura de Masson, pois, segundo Sylvia, esposa do psicanalista, "o vizinho ou a faxineira não compreenderiam" (Roudinesco 13, p. 195).

Lacan percebe bem essa contradição e faz dela uma definição do sublime, ao afirmar en passant, pouco antes de tratar do barroco, em seu Seminário XX, que "o sublime é o ponto mais elevado do que está embaixo” (Lacan 8, p. 18). O sublime está, portanto, ligado, no pensamento psicanalítico, ao sexual, ao gozo, a uma desmedida que, no 
famoso ensaio Tratado do sublime, escrito em grego nos primeiros séculos de nossa era e atribuído de maneira controvertida a Longuino, deveria ser domada por regras estritas para que se chegasse ao Grande. Ainda que o sublime aí comportasse certo risco, sendo, "por sua própria grandeza, escorregadio e perigoso" (Longin 12, p. 121, a tradução é minha) e podendo então levar a falhas, essas seriam suplantadas pela grandeza que contaminaria a obra como um todo, elevando-a.

Em Freud, encontramos a idéia de que a sublimação é um trabalho de transformação e ultrapassagem de algo baixo em direção ao que é socialmente idealizado. A sublimação chega quase a coincidir com o próprio trabalho de civilização ao ser definida como a substituição do objetivo sexual da pulsão, por definição desmedido, por uma meta não-sexual, eventualmente valorizada socialmente, grande, elevada. Por essa via, a sublimação designa uma característica fundamental da pulsão, a sua flexibilidade, o fato de ela ser votada a destinos múltiplos, a uma substituição e a um encadeamento de objetos, posto que seu primeiro objeto está irremediavelmente perdido, é inatingível. Ela ressalta, assim, a deriva própria ao funcionamento pulsional, deriva que Lacan chega a propor como termo capaz de traduzir o Trieb freudiano (cf. p. ex. Lacan 8, p. 102). A sublimação indica a extraordinária capacidade que possuem as pulsões sexuais, particularmente, de se distanciarem dos caminhos ligados à sua meta original (Freud 3, pp. 209-32). Ela seria, nessa perspectiva, o caminho que eventualmente transforma o sexual em belo, ou seja, que amortiza e civiliza a pulsão, à maneira do recalcamento, graças à plasticidade a ela inerente.

No entanto, a sublimação é tomada como um destino distinto e mais saudável, por assim dizer, que o recalcamento; ela guarda uma potência transgressora, uma possibilidade de ultrapassagem do recalcamento que também diz respeito, diga-se de passagem, à questão espinhosa de caracterizar o que realiza uma análise. Sabemos que, em alquimia, o termo sublimação indica a possibilidade de um salto na cadeia de transformações dos elementos, indo-se, por exemplo, diretamente do estado sólido ao gasoso, na busca incansável da pe- dra filosofal. A etimologia do termo não deixa de indicar, além da idéia de deslocamento para o alto, a conotação de transposição de um limiar (limen sendo "limite", em latim).

Não é à toa que Freud teria resolvido destruir, segundo seu editor inglês, o manuscrito dedicado a essa noção na leva de textos metapsicológicos dos anos dez (Strachey 14, p. 112). Em psicanálise, a sublimação é problemática: ela confirma a oposição entre o sexual e a cultura, a pulsão sexual e as pulsões de autoconservação, indicando uma via privilegiada de resolução do conflito inerente ao homem; ao mesmo tempo e estranhamente, ela reverte o caminho da civilização e reencarna, por assim dizer, o ideal. Apenas no limiar da década de 1920, com o surgimento da pulsão de morte, será possível retomar essa contradição para assumir a desmedida como inerente à estética, e ressaltar o conflito, a contradição sem resolução, como fundamental tanto à arte como à psicanálise, com a noção de Estranho (Unheimliche).

\section{O Estranho}

Ao mesmo tempo em que escreve o bombástico Além do princípio do prazer, Freud retira de sua gaveta e retrabalha o esboço realizado anos antes sobre o estranho. $\mathrm{O}$ psicanalista raramente seria levado a investigações estéticas, afirma ele na abertura desse escrito, pois

opera em outras camadas da vida mental e pouco tem a ver com os impulsos inibidos em sua meta, amortecidos e dependentes de tantas constelações concomitantes que são habitualmente o material da estéti-

ca (Freud 4, p. 229.)

Do belo e da harmonia o psicanalista não teria nada a dizer, ele que se ocupa do sexual e do conflito, da desmedida. Ele se contentaria em debruçar-se, então, sobre um domínio da estética pou- 
co explorado, o do Unheimliche. Mais do que se ocupar de uma noção específica dentre outras, porém, Freud tratará aí de forjar uma nova categoria que, podemos dizer, vem tomar no pensamento psicanalítico o lugar reservado ao belo e ao sublime na estética.

O Estranho diz respeito a uma categoria do assustador, do angustiante, que Freud caracterizará como sendo por definição contraditória, por remeter ao que é conhecido, há muito familiar. "Unheimliche nomeia", segundo Shelling citado por Freud, "tudo aquilo que deveria ficar no secreto e no oculto, mas é posto em evidência” (Freud 4, p. 235). É de um certo agenciamento significante que se trata, mais fundamentalmente: o termo toma a conotação, segundo a longa pesquisa semântica realizada pelo psicanalista, tanto de "estranho" quanto de "familiar" (heimlich), apesar do prefixo un- vir negar o radical heim.

Não me cabe aqui destrinchar a profusão de reflexões estéticas em que o belo e o sublime tomam matizes complexos e variados. Pontualmente, gostaria apenas de lembrar algumas passagens de Hegel, nas suas lições berlinenses que constituem a Introdução à estética, onde ele trata do sublime como algo ligado a um primeiro momento da produção artística na história da humanidade, o momento correspondente à arte simbólica e à arte oriental. Aí a idéia se apresentaria sob uma forma que lhe é "alheia, inadequada, não é outra sendo a matéria natural, sensível em geral". Tentando adequar a si essa forma, a idéia, ainda "desmedida", tratará dela de "maneira negativa, tenta elevá-la a si e o faz de forma igualmente desmedida, triturando-a, violentando-a e nela se derramando. Nisso consiste o sublime (...)" (Hegel 5, p. 133). O sublime toma, aí, da violência e da desmedida, do conflito entre forma e idéia, sua própria força.

$\mathrm{Na}$ arte clássica, que se sucede como segundo momento da produção artística, o sensível deixa de ser para Hegel o natural, e a forma torna-se perfeitamente de acordo com seu conceito. Contudo, o terceiro tempo, o do Romantismo, virá representar a síntese da contradição entre esses dois momentos, pois o cris- tianismo traz uma ruptura entre realidade e idéia que leva a uma retomada do conflito que define o sublime, ao mesmo tempo em que toma o conteúdo de que se trata "espiritual” e não mais diretamente sensível.

O novo conteúdo aí obtido já não está ligado à representação sensível, mas encontra-se liberado dessa correspondência direta que, reconhecida como de natureza negativa, é vencida, superada e transformada em uma correspondência, uma unidade desejada e consagrada pelo espírito. Neste sentido pode-se dizer que a arte romântica é um esforço da arte em superar a si mesma, sem por isso sair dos próprios limites da arte(Hegel 5, p. 141).

O Tratado do sublime ressoa, sem dúvida, nessas elaborações hegelianas, assim como influenciará Kant e dará um importante elã ao Romantismo a partir de sua tradução para o francês, feita por Boileau no século XVII. Essa obra encontra ecos ainda no famoso prefácio a Cromwell, publicado por Victor Hugo em 1827. Para o grande escritor francês, o belo, "esta beleza universal que a Antigüidade derramava solenemente sobre tudo, não deixava de ser monótona" (Hugo 7, p. 33); assim o sublime necessitará de contrastes, precisará do grotesco, do vil, precisará ser contraditório. Essa tensão é rapidamente resolvida, porém, em uma espécie de síntese, pois o grotesco, como um "termo de comparação", faz com que possamos elevar para o belo uma "percepção mais fresca e mais excitada" (ibidem). Teríamos, então, que "o contato do disforme deu ao sublime moderno alguma coisa de mais puro, de maior, de mais sublime enfim que o belo antigo" (Hugo 7, p. 34).

Ao contrário da síntese que acompanha em Hegel e em Hugo o sublime em sua maior realização, o Unheimliche caracteriza-se, estruturalmente, por manter intacta a tensão entre os dois termos opostos que o definem - o estranho e o familiar. Entre eles não há conciliação, nenhuma síntese permite ultrapassar tal contradição. 
Entre o que fica oculto e o que aparece e é posto em evidência, para aludir à definição de Shelling, o Estranho inaugura uma visibilidade opaca, ou melhor, uma alternância constitutiva do olhar - e do sujeito. Ao longo estudo a respeito do termo Unheimlich segue-se como sabemos, no texto freudiano, uma leitura do famoso conto "O Homem da Areia”, de E. T. A. Hoffmann. Freud vê nesse conto fantástico uma potência de inquietante estranheza oriunda da articulação, aí magistralmente realizada, entre olhar e castração. O motivo da perda da visão, dos olhos que seriam arrancados pela figura lendária do homem de areia, na ameaça feita às crianças que não quisessem ir dormir, refletiria a ameaça de castração proferida pelo pai. Não é à toa que a língua refere-se a algo extremamente importante como sendo a menina dos olhos, a pupila de alguém.

A imagem dá notícias da castração, convocando a se atualizar o momento de constituição de si que é imagético e concebido através do encontro do bebê com sua imagem no espelho, como avança Lacan em seu famoso "Estádio do espelho". Assim, um importante motivo de estranheza é, para Freud, o do duplo, tão explorado pela literatura. O próprio psicanalista reencontra seu duplo em uma viagem de trem, numa "aventura" por ele contada em uma nota a seu texto. A porta espelhada anexa a seu compartimento de viagem abrira-se com um solavanco e Freud vira então entrar um "senhor de idade, de roupão e boné de viagem” (Freud 4, p. 262). Apenas quando ia se levantar, para avisar a esse homem de aparência francamente desagradável que ele entrava no compartimento errado, Freud se dá conta de que está diante de sua própria imagem refletida no espelho. Freud se estranha no espelho, e tal estranhamento acompanha sempre, ainda que de maneira sutil, o reconhecimento no espelho que inaugura o eu. Quando este se constitui, ele ao mesmo tempo se estranha, dividindo-se na imagem, figurando nela a operação que o divide por sua entrada, na linguagem, no simbólico, denominada por Freud de castração, para marcar sempre sua incidência corporal. Assim o duplo é inicialmente, na pluma de Freud, uma garantia nar- císica, mas torna-se posteriormente um inquietante "anunciador da morte" (Freud 4, p. 247). Ou melhor, a imagem convoca a imagem corporal, constitutiva do sujeito, que é ao mesmo tempo narcísica e mortífera, pois reinsere de maneira insidiosa a castração, remetendo ao que não é visível, pois é exatamente o que falta à imagem, ao mesmo tempo em que a sustenta.

\section{A Coisa e sua in-dignidade}

Com o Estranho, o campo da arte é irremediavelmente afastado das altas realizações nas quais a pulsão é amortecida e reformulada socialmente, para se localizar no terreno angustiante do olhar em suas relações com a castração (mesmo no domínio da literatura), através de um arranjo significante que refaz o conflito irresolúvel entre Eros e a pulsão de morte. A partir dessa configuração, o movimento pulsional não será mais ressaltado em sua possibilidade de elevar-se além do sexual, mas se tornará prioritariamente o da repetição do mesmo, ainda que minimamente transfigurado, em busca da retomada da própria origem e causa última do desejo, a Coisa (das Ding).

O objeto primordial é irremediavelmente perdido e, portanto, abre as portas para toda uma cadeia de substituições, inaugurando o desejo como deriva, como já dissemos. Esse objeto permanece, contudo, como "excluído no interior", nas palavras de Lacan em seu Seminário VII (Lacan 9, p. 122). Ele cava um vazio no seio do sujeito, à maneira do vaso que se constitui em torno do vazio. É em uma conversa cerrada com a conferência de Heidegger sobre a Coisa que Lacan, pinçando em poucas ocorrências na obra de Freud o termo das Ding, faz dela um irrepresentável que só aparece velado ou se faz presente por suas ruínas, os objetos que fugazmente parecem tomar seu lugar. Que é uma coisa? - já se perguntava Heidegger. O vaso, esse objeto capaz de indicar com certeza, em escavações arqueológicas, a presença do homem, permitirá que o filósofo prossiga em sua ques- 
tão para definir a coisa como constituída por um vazio. "A coisidade do vaso", diz ele, "não reside, de modo nenhum, na matéria de que ele consiste, mas no vazio que contém" (Heidegger 6, p. 123). O vaso, como bem nota Lacan, cria o vazio e, ao mesmo tempo, introduz a perspectiva de vir a ser preenchido. Isso fará o psicanalista afirmar que "é a partir desse significante modelado que é o vaso que o vazio e o cheio entram como tais no mundo, nem mais nem menos, $\mathrm{e}$ com o mesmo sentido" (Lacan 9, p. 145). Se o vaso pode se encher é porque em sua essência ele é vazio. O vaso "encarna”, é a figuração concreta disso que estranhamente introduz e mantém em tensão a oposição entre vazio e cheio. Ao mesmo tempo vazio e cheio, esse significante agencia uma contradição unheimlich, exatamente como o significante Unheimliche, alçado por Freud a uma posição central para a estética.

Desse modo, o vaso oferece a Lacan, através de Heidegger, um modelo da Coisa como pura perda, em última instância, mas que pode ser contornada por uma operação significante (uma operação de modelagem do Significante, como sugere o trecho acima, em que Lacan caracteriza o vaso como "significante modelado"). Tal operação de sublimação consistiria em "elevar o objeto (...) à dignidade da Coisa” (Lacan 9, p. 133), em que ressoa a fórmula de Lévi-Strauss, publicada alguns anos antes, segundo a qual a arte confere à obra "a dignidade de um objeto absoluto” (Lévi-Strauss 11, p. 45). Qualquer objeto poderia ser alçado a tal "dignidade" - uma roda de bicicleta, por exemplo, no primeiro readymade produzido por Marcel Duchamp em 1913. Basta uma mínima operação significante sobre o objeto, um giro em relação à sua posição habitual, para que o significante Roda de bicicleta, tornado título, se descole de seu significado habitual e re-apresente sua coisidade, ou seja, apresente-se como contorno do vazio, remetendo ao objeto perdido.

Ou ainda, em um exemplo mais escandaloso, basta realizar um quarto de giro em um urinol, desses de sanitários públicos, retirandoo de sua posição vertical, e intitulá-lo Fonte (1917), para fazer dele uma obra de arte. Essa obra nos interessa aqui particularmente, pois nela se apresenta, diferentemente da roda de bicicleta, o caráter abjeto do objeto qualquer que é resto da Coisa, o objeto $a$ do léxico lacaniano, o objeto que se perde novamente, a partir da queda da Coisa, e que se concretiza nos produtos que saem do corpo, nos objetos-abjetos perdidos oferecidos ao Outro, que são o xixi, as fezes, os olhos no "O homem de areia" etc. A Fonte ressalta, ainda, em sua ausência mesma, o corpo de onde sai esse produto, a fonte da urina, a fonte que é a pulsão, em toda sua desmedida. Ao elevar esse objeto à dignidade de um objeto absoluto, sua abjeção não é aí deixada de lado em prol de uma elevação, mas, pelo contrário, é ressaltada, retomada, posta em relevo. A sublimação, aqui, eleva o objeto à indignidade da Coisa.

É muito amplo o campo da produção artística, principalmente contemporânea, que explora essa dimensão de indignidade, de abjeção, refazendo na sublimação o caminho inverso à dessexualização, para dar lugar ao abjeto e recolocar em movimento a pulsão em sua desmedida, convocando o gozo. In-dignidade e dignidade seriam, nessa perspectiva, mantidas em tensão na sublimação, como o Unheimliche, refazendo esse arranjo significante que é uma modelagem do significante. Tal modelagem comporta uma dimensão de criação, ao refazer o vazio em torno do qual se constitui o significante.

\section{O sujeito e o ato criador}

Tal criação, se diz respeito aos objetos e à Coisa, concerne também radicalmente ao sujeito. Para Heidegger, o vaso (Gefass) contém (fasst) o vazio. O oleiro que forma em seu torno "paredes e fundo", diz o filósofo,

não fabrica propriamente o cântaro. Apenas conforma a argila. Não; conforma o vazio. Por ele, nele e a partir dele, o oleiro modela a argila numa forma. Em primeiro lugar e sempre, o oleiro "capta e concebe" 
(fasst) o incaptável e inconcebível (das Unfasslich) do vazio, e o produz, como continente, na forma do vaso. O vazio do vaso determina cada gesto do produzir (Heidegger 6, p. 123)

O próprio oleiro “contém” (fasst, apreende e concebe), como o vaso, o que não se pode conter (das Unfasslich: "o que não se pode conter", e também "o que não se pode conceber"), ao criar o vaso. Cada gesto criador é determinado pelo vazio, produz-se dele, é ex-nihilo. $\mathrm{O}$ ato criador é então esburacado, implica em um certo esvazianento do lugar do sujeito; há um certo exílio do autor na realização de sua obra. Duchamp ressalta também, com seus readymades, esse aspecto da criação. Ao tomar objetos industrializados como uma roda de bicicleta e um urinol, ele põe em questão a autoria da obra. Esta situa-se aí em apenas um gesto, e subtrai-se à possibilidade, tradicionalmente explorada por intérpretes e críticos, de se buscar na obra elementos da subjetividade do artista. $\mathrm{O}$ artista é levado, no ato criador, a renunciar ao seu lugar de sujeito em prol do vazio, e nesse mesmo gesto remodela-se como sujeito, sujeito um tanto oculto de si mesmo, um tanto estranho, reconstituindo-se pela divisão mesma que o constitui, segundo a psicanálise.

O artista, como nota Duchamp ao falar do ato criador em conferência de 1957, não é capaz de descrever objetivamente as decisões que toma durante o processo de criação de uma obra, e não detém "papel algum no julgamento do próprio trabalho" (Duchamp 1, p. 198). Há necessariamente uma "falha", uma "inabilidade" do artista, ainda segundo Duchamp, em "expressar integralmente sua intenção", e é nesse descompasso entre o que se intenciona fazer e o que realmente se produz que residiria o "'coeficiente artístico pessoal' contido na obra" (Duchamp 1, p. 189). Se tal coeficiente é "pessoal", ele despersonaliza, ele é uma medida da estranheza a que se vê submetido o criador ao realizar uma obra, justo o contrário de uma confirmação de sua identidade.

Também o que opera em um tratamento analítico, segundo Lacan, é um ato. $\mathrm{O}$ ato analítico, noção que o psicanalista propõe ape- nas alguns anos após a conferência de Duchamp, aponta para o fato de que, na fala do analista, talvez seja fundamentalmente operante a enunciação, mais do que o enunciado. Isto basta para que se perceba que a fala é ato, e para que se retire o acento da propalada interpretação analítica, que conteria uma significação, em prol da criação significante a que daria lugar a intervenção do analista. $\mathrm{O}$ analista, afirma Lacan, "é por não pensar que ele opera" (Lacan 10, p. 377). Fazendose e re-fazendo-se em torno do vazio, o que lhe seria possível graças a sua própria análise, o analista poderia dar lugar ao ato que convida o analisando, por sua vez, a alguma criação. (Penso em um analisando que me disse certa vez de sopetão: "você é um buraco".)

O exílio do artista como condição da obra parece abri-la à participação de outros criadores, só depois, no momento de sua recepção. Para Duchamp, o ato

não é realizado pelo artista sozinho; o público estabelece o contato entre a obra de arte e o mundo exterior, decifrando e interpretando suas qualidades intrínsecas e, desta forma, acrescenta sua contribuição ao ato criador (Duchamp 1, p. 189)

Também a intervenção do analista só se realiza como obra na transferência, ou seja, desde que o analisando a retome em sua própria criação. A criação em ato, seja ela em análise ou em arte, conformando-se a partir do vazio e mantendo-o operante, mesmo ao preenchê-lo um tanto, convoca o outro a ocupar esta mesma posição, tornando-se um tanto vaso e sendo convidado também a retomar essa modelagem do significante que re-modela, no mesmo golpe, também o sujeito. Duchamp chega a dizer, mais radicalmente, referindo-se à pintura: "os olhadores fazem o quadro" (Duchamp 1, p. 247). O poder da obra de arte de enlaçar seu público - seu poder, digamos, de sedução - está intimamente ligado à questão do "reconhecimento social" que Freud várias vezes sublinha como essencial para o sucesso da sublimação. Há um laço social realizado pela obra, 
a partir do reestranhamento a que ela convida o sujeito. Ao apresentar-se no lugar de in-dignidade da Coisa, a obra faz uma promessa que ela não cumprirá totalmente ela nos convida a refazer o que ela não é, enganchando-nos à maneira do amor, que é, para Lacan, sempre dar o que não se tem.

\section{Referências bibliográficas}

1. DUCHAMP, Marcel. "Le processus créatif”. In Duchamp du Signe. Paris: Flammarion, 1994

2. FREUD, Sigmund. "Três ensaios sobre a teoria da sexualidade". In Edição Standard Brasileira das Obras Psicológicas Completas de S. Freud. Rio de Janeiro: Imago, vol. VII, 1996 (1905)

3. _ . "Triebe und Triebeschicksale". In Gesammelte Werke. Londres: Imago, tomo X, 1946a (1915).

4. — . Das Unheimliche. In: Gesammelte Werke. Londres: Imago, tomo XII, 1946b (1915).

5. HEGEL, Georg. W. F. Introdução à Estética. Barcelona: Nexus, 1985.

6. HEIDEGGER, Martin. “A Coisa”. In DE SOUZA, E. Mitologia. Lisboa: Guimarães Editores, 1984

7. HUGO, Victor. Do grotesco e do sublime. São Paulo: Perspectiva, 2002.

8. LACAN, Jacques. Le Séminaire, Livre XX: Encore. Paris: Seuil, 1975.

9. LACAN, Jacques. Le Séminaire, Livre VII: L'éthique de la psychanalyse. Paris: Seuil, 1986.

10. LACAN, Jacques. "L'acte psychanalytique". In Autres écrits. Paris: Seuil, 2001.

11. LÉVI-STRAUSS, Claude. La pensée sauvage. Paris: Plon, 1962.

12. LONGIN, O. Traité du Sublime. [S.l.]: Le Livre de Poche/Bibliothèque Classique, 1995.

13. ROUDINESCO, Elizabeth. Jacques Lacan: esboço de uma vida, história de um sistema de pensamento. São Paulo, Companhia das Letras, 1994.

14. STRACHEY, James. "Introdução aos escritos sobre metapsicologia”. In Edição Standard Brasileira das Obras Psicológicas Completas de S. Freud. Rio de Janeiro: Imago, vol. XIV, 1996 (1969).

\section{Observações sobre o tema da atemporalidade em Freud, Kant e Bergson}

Hélio Lopes

Professor da Universidade Federal de Ouro Preto (UFOP) 